\title{
The effects of referent and reward power upon social conflict*
}

\author{
BARRY R. SCHLENKER, THOMAS V. BONOMA, and JAMES T. TEDESCHI \\ State University of New York at Albany, Albany, N.Y. 12203 \\ SVENN LINDSKOLD \\ Ohio University, Athens, Ohio 45701 \\ and \\ JOANN HORAI \\ Hofstra University, Hempstead, L.I., N.Y. 11550
}

Intermittent contingent promises were sent to male Ss during a mixed-motive interaction by either a liked or disliked simulated player. The $\mathbf{S}$ compliance was rewarded either $10 \%$ or $90 \%$ of the time. Although neither factor affected compliance, liking for the promisor did induce more behavioral trust, more cooperation on power-irrelevant interactions, and caused $S s$ to evaluate the promisor more favorably after the interaction.

French \& Raven (1959) have distinguished two important bases of interpersonal power-reward power and referent power. The former refers to the source's ability to promise and provide rewards, while the latter denotes the degree of identification, attraction, or liking which exists between a source and target in an influence relationship. The combined effects of these power bases, however, might function in a manner different from that of either power mode alone during influence interactions. For example, it might be expected that promises would be more effective in ameliorating conflict between friends than between nonfriends.

To test the above relationship, the present experiment employed a 2 by 2 factorial design. The Ss were induced to believe that they were participating in the experiment with another person, who was either attitudinally similar or dissimilar to themselves. A simulated player (SP) was given options intermittently during the course of play in a Prisoner's Dilemma (PD) game to send contingent promises requesting the $S$ 's cooperative response as a quid pro quo for a positive side payoff. The objective probability that the reward would be given when the $S$ complied to the SP's requests was set at either $10 \%$ or $90 \%$. It was expected that compliance to promises would be greater when the Ss liked the promisor and when the objective probability of reward was high. In addition, it could be expected that $S s$ in the similarity conditions would be more cooperative on power-irrelevant iterations of the

*The present research was supported by a fellowship from the National Science Foundation to the senior author, by Grant No. ACDA-0331 from the U.S. Arms Control and Disarmament Agency to the second author, and by Grant No. GS-27059 from the National Science Foundation to the third author.
$P D$ than $S s$ in the dissimilarity conditions.

SUBJECTS AND APPARATUS

Forty male Ss partially fulfilled an introductory psychology course requirement at the University of Miami (Florida) by participating in the experiment. The Ss faced a fully automated apparatus which contained: the 2 by 2 payoff matrix, each cell of which could be illuminated separately to indicate S's and SP's point outcomes after each trial; two switches, one for Choice 1 (cooperative) and one for Choice 2 (competitive) strategy selections; two add-subtract cumulative counters which kept running totals of both players' scores; a series of slots for printed messages, each with a light for incoming and a button for outgoing communications; and a series of lights serving as prompters and guides for the correct sequencing of events during the interaction. The outcomes in the payoff matrix were symmetrical and, following the notation of Rapoport \& Chammah (1965), contained the values: $\mathrm{R}=4, \mathrm{~S}=-5, \mathrm{~T}=5, \mathrm{P}=-4$. PROCEDURE

Upon arrival at the laboratory, each $S$ was taken to a testing cubicle and was asked to fill out a Survey of attitudes (Byrne, 1961). The attitude survey asked Ss to indicate, on 6-point scales, their beliefs about items concerning politics, sex, religion, etc.

The E took S's completed survey of attitudes and falsified another so as to express all attitudes either highly similar or highly dissimilar to those expressed by $S$. The falsified survey was brought to $S$, and he was asked to examine it carefully and to record his impressions of the person who filled out the survey on an interpersonal judgment scale (IJS: Byrne, 1961). Two critical items in the IJS asked Ss how much they thought they liked the other person and how much they thought they would enjoy working with the other person in an experiment. The latter two measures provided the dependent variable assessment of the attraction inducement.

Each $\mathrm{S}$ was informed that he and the "other person" he had just rated would participate together in a joint decision task. The $S$ was then taken to a cubicle containing the PD apparatus and given instructions about the rudiments of $P D$ play and the nature of the interdependent point outcomes. All Ss were instructed to obtain as many points as they could during the interaction, an individualistic set. The Ss were informed that the SP could send the posted promise message at any time during the interaction by illuminating a white communication light on the S's board and that the SP could reward $S$ if the latter did as the message requested. The promise message available to the SP read: "If you make Choice 1 on the next trial, I will add 10 points to your counter." Each time $S$ received a message from the SP, he was constrained to transmit one of three available reply messages to the SP: (M1) "I will make Choice 1 on the next trial"; (M2) "I will make Choice 2 on the next trial"; or (M3) "I do not wish to disclose my intentions." The Ss were told that they could not initiate communications. No mention of words such as "game," "opponent," "cooperation," "promise," etc., was made at any time.

The objective probability of reward for $\mathbf{S}$ compliance to the promises could not be held constant within probability conditions if $\mathbf{S}$ compliance was free to vary, so a criterion of 10 compliant responses to the promises was set for all Ss. When $S$ had complied 10 times, no further promises were sent. Since the number of unsuccessful promises (promises to which $S$ noncomplied by making Game Choice 2) were free to vary, consistently compliant Ss experienced fewer unsuccessful promises before reaching the criterion. The number of unsuccessful promises, therefore, was chosen as an indirect index of behavioral compliance. For half the Ss, the probability of receiving the reward was set at $10 \%$, while for the other half of the Ss, the probability was set at $90 \%$. In the $10 \%$ probability conditions, Ss were given the promised reward only after the fifth compliant response, while in the $90 \%$ probability conditions, Ss were rewarded after all but the fifth compliant response.

A fixed number of options was provided so that the SP could potentially send a promise message to a $\mathrm{S}$ prior to predesignated PD trials. Two promise options were placed 
randomly within each block of $10 \mathrm{PD}$ trials over the 150 trials which were played. The SP attempted to establish one successful promise (i.e., promise to which $\mathrm{S}$ complied by making Game Choice 1) per block of 10 trials. If the pace was not maintained, both promise options were used in each successive block until the pace was reestablished. In no case could more than two promises be sent in any block. The SP was 50\% cooperative over all 150 trials (as predetermined by a table of random numbers) and was $100 \%$ cooperative on message occasions.

At the conclusion of PD play, Ss rated the SP on a shortened form of the semantic differential (SD: Osgood et al, 1957) and a second time on the IJS.

\section{RESULTS}

The pretest scores on the IJS indicated that the attraction manipulation was successful $(F=79.70, \quad d f=1 / 36, \quad p<.001)$. Similar Ss liked the SP more $(\bar{X}=11.5, \sigma=1.2)$ than did dissimilar Ss $(\overline{\mathrm{X}}=6.3, \sigma=2.3)$. The induced differences were maintained throughout the interaction, as indicated by posttest IJS scores $(F=34.27, \quad d f=1 / 36, \quad p<.001)$; similar Ss still liked the SP more $(\overline{\mathrm{X}}=10.9, \sigma=1.9)$ than did dissimilar Ss $(\bar{X}=7.6, \sigma=1.6)$.

Although no differences were found on the measure of compliance (all ps $>.10)$, a covariance analysis ${ }^{1}$ of cooperative choices on power-irrelevant $P D$ trials revealed a main effect of attitude similarity $(\mathrm{F}=7.25, \mathrm{df}=1 / 35, \mathrm{p}<.01)$; similar Ss cooperated proportionately more often $(\overline{\mathrm{X}}=.455, \sigma=.153)$ than did dissimilar Ss $(\overline{\mathrm{X}}=.330, \sigma=.129)$.

Rapoport \& Chammah (1965) made trust operative in the $P D$ as a cooperative choice by a player on Trial $n+1$ immediately following competitive choices by both players on Trial $n$. A main effect of attitude similarity was found on this measure of behavioral trust $(\mathrm{F}=10.63$, $\mathrm{df}=1 / 35, \mathrm{p}<.002)$. The Ss displayed more behavioral trust when they liked the SP $(\overline{\mathrm{X}}=.479, \sigma=.181)$ than when they disliked the SP $(\overline{\mathrm{X}}=.314$, $\sigma=.116$ ).

Covariance analyses of Ss' communicative acts revealed only a main effect of similarity ( $F=7.25$, $\mathrm{df}=1 / 35, \mathrm{p}<.01$ ) on the frequency with which the reply message announcing compliant intentions (M1) was sent by Ss. If Ss liked the promisor, they indicated their intention to comply less often $(\bar{X}=7.4, \sigma=3.2)$ than when they disliked the SP $(\bar{X}=9.7, \sigma=3.3)$. No other effects on the frequency or truth with which Ss used messages were found.

Finally, a similarity main effect was found on the postinteraction scores on the evaluative subscale of the SD $(\mathrm{F}=4.54, \mathrm{df}=1 / 35, \mathrm{p}<.04) ;$ Ss rated a liked SP more favorably $(\bar{X}=2.9$, $\sigma=3.3)$ than a disliked $\mathrm{SP}(\overline{\mathrm{X}}=0.6$, $\sigma=3.6)$.

\section{DISCUSSION}

The similarity-dissimilarity manipulation was successful in inducing and maintaining the desired levels of high and low interpersonal attraction throughout the mixed-motive interaction. The failure of attraction to mediate compliance to contingent promises is consistent with several other studies combining interpersonal attraction with the message-modified PD. Schlenker \& Tedeschi (in press) found that a S's liking for a simulated target did not affect the former's preference for threats over promises as a mode of power. Smith, Monteverde, \& Tedeschi (1971) found that the attraction of Ss for an SP who made unilateral noncontingent promises to cooperate on certain trials of a PD had no effect on the Ss' willingness to reciprocate promises or to cooperate on message-relevant trials. On the other hand, interpersonal attraction clearly mediates attitude change to persuasion attempts (cf. McGuire, 1969) and conformity to group pressures (cf. Kiesler \& Kiesler, 1969). It is plausible that the explicit terms of exchange in the mixed-motive conflict situation characterizes the relationship of the interacting parties as economic rather than social, and hence interpersonal attraction becomes irrelevant. Blau (1964) distinguishes social exchange as one where the amount of timing of reciprocity is left implicit. When the SP offered Ss 10 points if they would make the cooperative choice, it was clear that a fixed exchange was explicitly being proposed. Even when noncontingent promises were used in the Smith et al study, it was rather unambiguous that the promisor wanted the target to reciprocate immediately so that they both could share equal winnings.

On the other hand, on those $\mathrm{PD}$ trials when no explicit communications were exchanged and the relationship could be characterized as implicit with regard to the timing and amount of reciprocity, the attraction of Ss for the SP became relevant. The Ss who were similar to the promisor closely reciprocated the latter's programmed degree of cooperativeness $(50 \%)$ in their own play $(46 \%)$, while Ss who were dissimilar to the SP displayed low levels of cooperation (33\%). Swingle (1966), Kaufmann (1967), and
Tornatzky \& Geiwitz (1968) also found that attraction directly mediated cooperative strategy selections in PD games.

In addition to directly ameliorating social conflict, attraction for the "opponent" led to the display of greater behavioral trust. In short, similarity led to overall conflict mitigation by increasing cooperation, trust, and outcome reciprocation. Distrust probably made it necessary for Ss who disliked the promisor to utilize more often the explicit reply message of intent to comply to the latter's requests to maintain the $54.6 \%$ compliance that both like and dislike Ss gave to the promisor's requests.

The failure of the probability of promise fulfillment manipulation to produce any effects in the experiment may be due to the sheer magnitude of the promised side payoff. Relative to the size of the matrix entries, the promised reward of 10 points was excessive and may have seemed unrealistic and irrational to Ss. In other words, the terms of exchange were so unfavorable to the party (SP) proposing the exchange that the plausibility of his communications were undermined, whatever probability he established for his promises.

\section{REFERENCES}

BLAU, P. M. Exchange and power in social life. New York: Wiley, 1964.

$B Y R N E, D$. Interpersonal attraction and attitude similarity. Joumal of Abnormal \& Social Psychology, 1961, 62, 713-715.

FRENCH, J. R. P., JR., \& RAVEN, B. H. The bases of social power. In D. Cartwright (Ed.), Studies in social power. Ann Arbor: Institute for Social Research, 1959. Pp. 150-167.

KAUFMANN, H. Similarity and cooperation received as determinants of cooperation rendered. Psychonomic Science, $1967,9,73-74$.

KIESLER, C. A., \& KIESLER, S. B. Conformity. Reading, Mass: Addison-Wesley, 1969.

McGUIRE, W. J. The nature of attitudes and attitude change. In G. Lindzey and E. Aronson (Eds.). The handbook of social psychology. Vol. 3, (2nd ed.) Reading. Mass: Addison-Wesley, 1969 . Pp. $136-314$.

OSGOOD, C. E., SUCI, G. J., \& TANNENBAUM, P. H. The measurement of meaning. Urbana: University of Illinois Press, 1957.

RAPOPORT, An, \& CHAMMAH, A. M. Prisoner's dilemma. Ann Arbor: University of Michigan Press, 1965.

SCHLENKER, B. R., \& TEDESCHI, J, T. Interpersonal attraction and the exercise of reward and coercive power. Human Relations, in press.

SMITH, R. B., II, MONTEVERDE, F., \& TEDESCHI, J. T. Interpersonal attraction and responsiveness to conciliatory promises. Mimeographed manuscript, State University of New York at Albany, 1971.

SWINGLE, P. G. Effects of the emotional relationship between protagonists in a two-person game. Joumal of Personality \& Social Psychology, 1966, 4, 270-279.

TORNATZKY, L., \& GEIWITZ, P. J. The effects of threat and attraction on 
interpersonal bargaining. Psychonomic Science, 1968, 13, 125-126. NOTE

1. Since the dependent measures on $\mathrm{Ss}^{\prime}$ degree of cooperation on nonmessage trials degree of behavioral trust, and frequency of reply messages were related to the number of promises sent to each $S$, analyses of covariance were performed on these measures with the number of unsuccessful promises serving as the covariate. All means reported for these variables have been properly adjusted. All other analyses were performed by standard analysis of variance techniques.

\section{CURRENT LITERATURE ON COMPUTERS}

BERNSTEIN N. (Moore School of Electrical ingineering, University of Pennsylvania, Philadelphia, $\mathrm{Pa}$. 19104). Quintupling the speed of the PDP-8 DF32 disk system for real-time use. Behavior Research Methods \& Instrumentation, 1971, 3, 92-94.

CHURCHILL, S. (Ontario Institute for Studies in Education, Toronto, Ontario, Canada), NAESS, L., \& OLIVIER, W. P. CAN-4, an advanced author language for $\mathrm{CAI}$, computer-based testing and psychological experimentation: PDP-9 implementation. Behavior $\mathrm{Research} \quad \mathrm{Methods} \quad \&$ Instrumentation, 1971, 3, 95-99.

COX, B. (University of Chicago, Chicago, ㄱl. 60637). Simulation of neural sets. Behavior Research Methods \& Instrumentation, 1971, 3, 81-84.

EMERSON, P. L. (Cleveland State University, Cleveland, Ohio 44115), CAMUS, E., \& RICHARDS, C. Two-voice music programming system: The PDP-9 as an automatic electronic organ. Behavior Research Methods \& Instrumentation, 1971, 3, 164-166.

FITZHUGH, R. J. (Computer Facility, Learning Research and
Development Center, University of Pittsburgh, Pittsburgh, $\mathrm{Pa}$. 15213), \& KATSUKI, D. The touch-sensitive screen as a flexible response device in CAI and behavioral research. Behavior Research Methods \& Instrumentation, 1971, 3, 159-164.

LAUER, G. (Science Center, North American Rockwell Corporation, Thousand Oaks, Calif. 91360). A real-time multiuser forground, single-user background system for the PDP.9 computer. Behavior

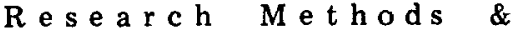
Instrumentation, $1971,3,103-105$.

LEWIS, J. L. (University of Oregon, Eugene, Oreg. 97403), BOIES, S. J., \& OSGOOD, G. W. Zoroaster: A multiprogramming system for psychological research. Behavior Research Methods \& Instrumentation, 1971, 3, 106-107. SCHWENN, P. T. (Department GYN/OB, University of Wisconsin Medical Center, Madison, Wis. 53706). "Time," a time-sharing moniter for the DEC LINC-8, PDP-8, and PDP-12. Behavior Research Methods \& Instrumentation, 1971, 3, 100-102. SCOTT, D. E. (Electrical Engineering Department), \& DZENDOLET, E. The PDP-8/I as a CAT. Behavior
Research Methods \& Instrumentation, 1971, 3, 79-81.

SPERLING, G. (Bell Telephone Laboratories, Murray Hill, N.J. 07974). Computer parasites and hosts: Practical advice on how to be a successful parasite at your host's computer installation. Behavior $\mathrm{R}$ es e a c h M e thods \& Instrumentation, $1971,3,147-148$.

SPERLING, G. (Bell Telephone Laboratories, Murray Hill, N.J. 07974 ). Flicker in computer-generated visual displays: Selecting a CRO phosphor and other problems. Behavior Research Methods \& Instrumentation, 1971, 3, 151-153.

THOMAS, P. A. V. (Electrical Engineering Department, University of Windsor, Windsor, Ontario, Canada), \& BALATONI, N. A hardware multiplier/divider for the PDP 8S computer. Behavior $R$ esearch $M$ ethods \& Instrumentation, 1971, 3, 89-91. 